\title{
Sex, gender and the pulmonary physiology of exercise
}

\author{
Paolo B. Dominelli $\mathbb{1}^{1}$ and Yannick Molgat-Seon $\mathbb{1}^{2,3}$ \\ Number 5 in the Series "Sex and gender in lung disease"
Edited by Jason Weatherald, Marc Humbert and Renata Riha
}

${ }^{1}$ Dept of Kinesiology, University of Waterloo, Waterloo, ON, Canada. ${ }^{2}$ Dept of Kinesiology and Applied Health, University of Winnipeg, Winnipeg, MB, Canada. ${ }^{3}$ Centre for Heart and Lung Innovation, Providence Health Care Research Institute, St Paul's Hospital, Vancouver, BC, Canada.

Corresponding author: Paolo B. Dominelli (paolo.dominelli@uwaterloo.ca)

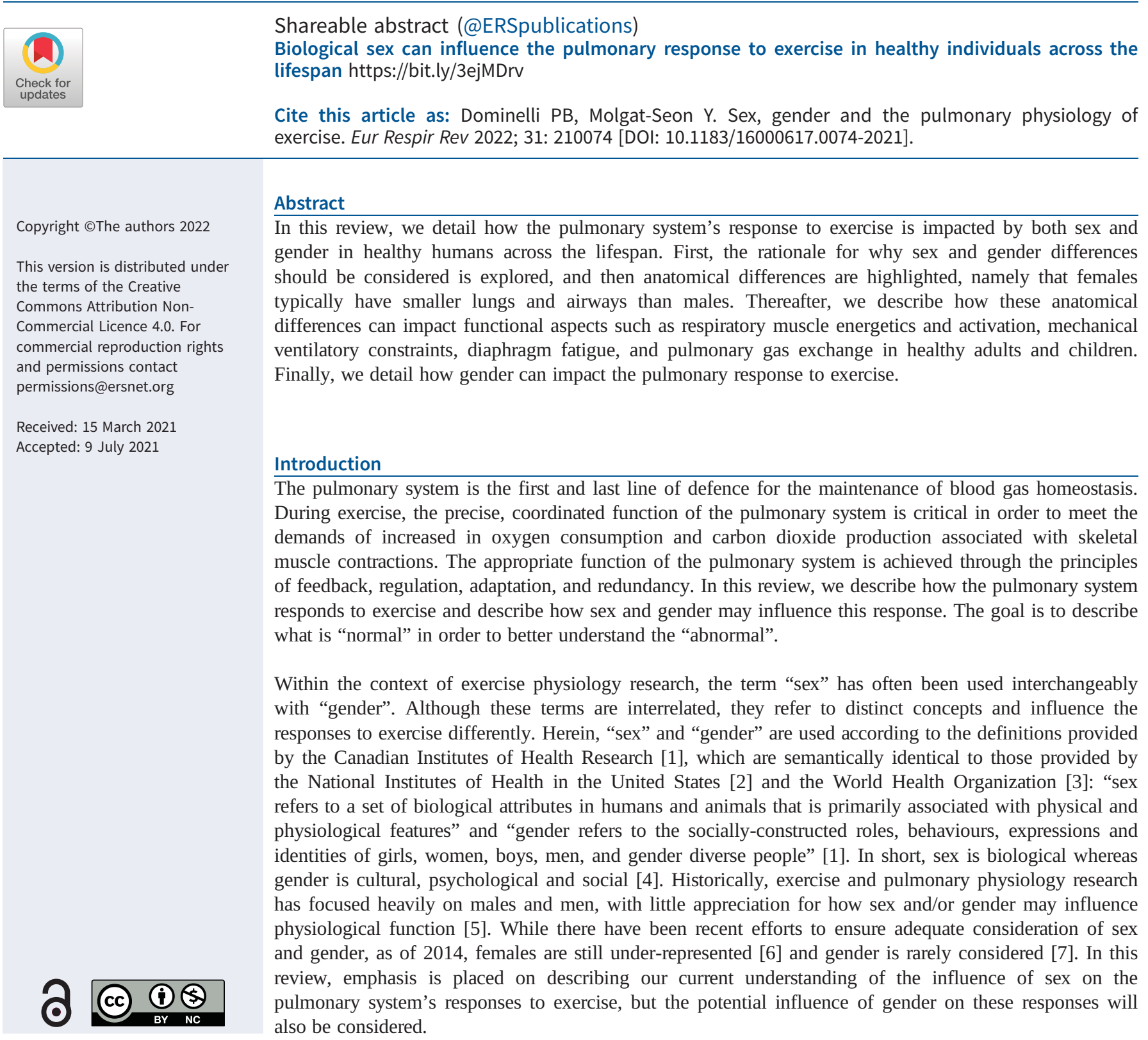


Making unbiased, sex-based comparisons

The biological attributes that determine sex are numerous and encompass several definitions [8], which implies that studying the influence of sex on human physiology can be complex. A common issue when determining the effect of sex on the responses to exercise concerns whether to make comparisons in absolute or relative terms. This problem is rooted in the fact that, on average, certain biological attributes that impact the physiological response to exercise differ between the sexes. For example, on average, height, body mass and lung size differ based on sex [9]. Thus, should we compare outcome variables in absolute (e.g. oxygen uptake in $\mathrm{L} \cdot \mathrm{min}^{-1}$, etc.) or relative (e.g. \% maximal oxygen uptake, etc.) terms? As we have previously argued [10], the best method of comparison depends on context. For example, relative comparisons are more appropriate when the effect of body size amplify or obscure differences between the sexes $[11,12]$. Conversely, absolute comparisons are more ecologically relevant since the difference in body size is itself influenced by sex [13]. There are approaches that can minimise the issues associated with making absolute or relative comparisons. Accounting for sex differences in biological attributes, such as body mass or fat-free mass, by normalising an outcome variable allows for comparison between the sexes without the influence of a confounding variable $[14,15]$. Matching the sexes based on a given factor, such as height or lung size, provides a similar benefit [16, 17]. However, each approach to evaluating sex differences and similarities in the physiological response to exercise has inherent benefits and drawbacks. While there are no set guidelines for making unbiased, sex-based comparisons, we propose that the chosen approach should be informed by the primary aim of the study and, where possible, the results should be reported in both absolute and relative terms.

\section{Underlying mechanisms of sex differences}

Three morphological differences in the pulmonary system are the putative mechanisms that underpin sex differences in the pulmonary physiology of exercise (table 1) [9-11, 13, 15, 17-41]. Specifically, there are well-documented sex differences in the luminal area of the central conducting airways, lung size, and the shape of the ribcage and lungs, which we describe individually below.

\section{Central conducting airways}

The large conducting airways (i.e., trachea to $\sim$ fifth generation bronchi) are responsible for the majority of airway resistance, the most important determinant of which is total luminal area. Early indirect evidence suggested that females have significantly smaller airways than males of similar lung size; however, it was unclear which airways were different [42]. Studies involving x-ray and acoustic reflectance measures noted that tracheal area was smaller in females than in males [43, 44]. Recently, studies involving computed tomography imaging demonstrated that females have smaller central conducting airways (i.e., trachea to third generation bronchi) and the difference persists when subjects are matched for lung size [18, 19] or height [17]. Upstream of the third generation, the magnitude of sex differences in airway size decreases; however, this may be due to the size of these airways approaching the resolution limits of computed tomography. Future studies using high-resolution imaging techniques, such as optical coherence tomography [45], are required in order to determine whether sex differences in airway morphology extend beyond the third generation [30].

TABLE 1 Summary of known sex differences in pulmonary system morphology and their impact on the pulmonary physiology of exercise

Key references

Morphological differences

- Males above the age of 14 years have proportionally greater airway luminal area of the large conducting airway (i.e., trachea to

$[15,17-20]$

the third generation) than females

- Males have larger absolute lung volumes and more alveoli than females

- Females have "prismatic" geometry of the ribcage and lung while males have "pyramidal" ribcage and lung geometry

Functional differences

- Higher $\mathrm{W}_{\mathrm{b}}$ and $\dot{V}_{\mathrm{O}_{2} \mathrm{RM}}$ for a given absolute $\dot{V}_{\mathrm{E}}$ during exercise in females compared to males

Due to a higher resistive component of $\mathrm{W}_{\mathrm{b}}$

- Females have greater activation of “extra-diaphragmatic" inspiratory muscles for a relative or absolute $\dot{V}_{\mathrm{E}}$ during exercise

Noted in the scalene and sternocleidomastoid muscles

- Highly trained males are less likely to develop expiratory flow limitation during exercise than highly trained females

- Females have a blunted respiratory muscle metaboreflex

- EIAH can occur in untrained females but does not appear to occur in untrained males

$[10,11,41]$

- Older females have a higher perception of dyspnoea at absolute and relative exercise intensities than older males

EIAH: exercise-induced arterial hypoxaemia; $\dot{V}_{\mathrm{E}}$ : minute ventilation; $\dot{V}_{\mathrm{O}_{2} \mathrm{RM}}$ : oxygen uptake of the respiratory muscles; $\mathrm{W}_{\mathrm{b}}$ : work of breathing. 
The physiological relevance of central airway size area is evident when considering the impact of airway cross-sectional area on flow resistance and patterns (i.e., laminar, transitional, or turbulent). At low flows (e.g., at rest), airflow is mostly laminar in all airways. As ventilation $\left(\dot{V}_{\mathrm{E}}\right)$ increases, flow becomes transitional and subsequently turbulent in the largest airways, where velocity is high. The transition to disorganised, turbulent flow patterns, which increases airflow resistance, is in part why the mechanical work of breathing $\left(\mathrm{W}_{\mathrm{b}}\right)$ increases curvilinearly with increasing $\dot{V}_{\mathrm{E}}$, and is thought to explain why females have a greater $\mathrm{W}_{\mathrm{b}}$ at a $\dot{V}_{\mathrm{E}}>\sim 50 \mathrm{~L} \cdot \mathrm{min}^{-1}$ (see below). Conversely, extensive branching of the airway tree progressively reduces airflow velocity, implying that even at maximal $\dot{V}_{\mathrm{E}}$, flow in the small airways is likely still laminar. Thus, if there were sex differences in small airways size, the corresponding influence of small airway resistance on $\mathrm{W}_{\mathrm{b}}$ is unlikely to have a substantial influence on sex differences in the pulmonary physiology of exercise in healthy adults.

\section{Lung volumes}

On average, males are taller than females, and therefore have larger lungs. Population-based studies indicate that males have larger absolute lung volumes than females even when matched for height [9, 21]. However, relative lung volumes and capacities are similar between the sexes. For example, the ratio of functional residual capacity (FRC) to total lung capacity (TLC) is similar in males and females. That FRC/ TLC is similar between the sexes suggests that the intrinsic elastic properties of the lung and chest wall are independent of sex.

\section{Shape of the ribcage and lungs}

The shape of the ribcage, lungs, and tracheobronchial tree also appear different between the sexes [22, 46]. In females, the shape of the ribcage and lungs is more "prismatic", whereas in males the ribcage and lungs tend to be more "pyramidal” [22, 23]. However, how these morphological differences impact physiological ones, particularly during exercise, are currently unknown. Differences in ribcage geometry would likely affect the angles at which the respiratory muscles contract, which could influence respiratory system kinematics [24] and potentially respiratory muscle activation and/or energetics. Future studies examining how the shape of the ribcage and lungs influences pulmonary system function are required.

\section{Response to dynamic whole-body exercise}

Here we describe how sex impacts the physiological response to dynamic whole-body exercise (table 1). We use "dynamic" to indicate the rhythmic contraction of muscle groups that produce movement, and "whole-body" to signify large muscle group exercise that elicits an integrative, rather than localised, response (i.e., substantial increases in $\dot{V}_{\mathrm{E}}$ and cardiac output). Typically, this is accomplished in a laboratory using a cycle ergometer or a treadmill.

\section{Ventilatory response to exercise}

At the onset of dynamic whole-body exercise, $\dot{V}_{\mathrm{E}}$ rapidly increases due to tidal volume $\left(V_{\mathrm{T}}\right)$ expansion and, to a lesser extent, an increase in breathing frequency. As exercise intensity progresses, $\dot{V}_{\mathrm{E}}$ rises in a linear manner until a threshold after which $\dot{V}_{\mathrm{E}}$ rises out of proportion to oxygen uptake $\left(\dot{V}_{\mathrm{O}_{2}}\right)$ [47]. The initial reliance on $V_{\mathrm{T}}$ minimises mechanical work [48, 49] and optimises alveolar ventilation [50]. Expanding $V_{\mathrm{T}}$ is achieved by decreasing end-expiratory lung volume below FRC to optimise the lengthtension relationship of the respiratory muscles, and increasing end-inspiratory lung volume up to $~ 80-90 \%$ of vital capacity. Once $V_{\mathrm{T}}$ reaches $\sim 60 \%$ of vital capacity, further increases in $\dot{V}_{\mathrm{E}}$ are achieved by increasing breathing frequency.

The "normal" ventilatory response to exercise described above is similar in males and females (figure 1a); however, owing to differences in size, absolute values will differ based on sex. For example, at maximal exercise, a female's $\dot{V}_{\mathrm{E}}$ is lower than a male's, but the relative increase in $\dot{V}_{\mathrm{E}}$ from rest is of similar magnitude. Likewise, males typically have larger absolute $V_{\mathrm{T}}$, but $V_{\mathrm{T}}$ plateaus at $\sim 60 \%$ of vital capacity in both sexes. On average, males have a higher absolute $\dot{V}_{\mathrm{O}_{2}}$ and carbon dioxide production $\left(\dot{V}_{\mathrm{CO}_{2}}\right)$ for a given relative work (i.e. fraction of maximal $\dot{V}_{\mathrm{O}_{2}}\left(\dot{V}_{\mathrm{O}_{2} \max }\right)$ ), which results in a greater $\dot{V}_{\mathrm{E}}$ to maintain blood gas homeostasis. Aerobic training or detraining alters these responses, but these effects do not differ based on sex. Nevertheless, males typically have a higher absolute and relative $\dot{V}_{\mathrm{O}_{2} \text { max }}$ due to sex differences that are unrelated to the pulmonary system (i.e., differences in haemoglobin mass) [51].

\section{Respiratory muscle energetics}

Increasing $\dot{V}_{\mathrm{E}}$ during exercise necessitates a corresponding increase in total $\mathrm{W}_{\mathrm{b}}$, which is the sum of the elastic, resistive, and inertial work, and is performed exclusively by the respiratory muscles. At typical breathing frequencies observed at maximal exercise (i.e., $<70$ breaths $\cdot \mathrm{min}^{-1}$ ) the inertial work is a minimal [52] 
and likely similar in males and females, so it will not be discussed further. The relationship between $\mathrm{W}_{\mathrm{b}}$ and $\dot{V}_{\mathrm{E}}$ is curvilinear, whereby $\mathrm{W}_{\mathrm{b}}$ rises exponentially with increasing $\dot{V}_{\mathrm{E}}$. The point when $\mathrm{W}_{\mathrm{b}}$ rises out of proportion to $\dot{V}_{\mathrm{E}}$ differs between individuals and likely reflects the transition to turbulent flow in the central airways [53]. For a given $\dot{V}_{\mathrm{E}}>50-60 \mathrm{~L} \cdot \mathrm{min}^{-1}$, females have a higher absolute $\mathrm{W}_{\mathrm{b}}$ than males [13, $25,27,28,54]$, regardless of aerobic fitness. Given that the elastic properties of the lungs and ribcage are similar in males and females, the elastic component of $\mathrm{W}_{\mathrm{b}}$ during exercise does not differ based on sex. However, females have a higher resistive component [25, 26, 28, 29] of $\mathrm{W}_{\mathrm{b}}$, presumably due to sex differences in airway size [30, 45].

Similar to other skeletal muscles, there is a linear relationship between external work (i.e., $\mathrm{W}_{\mathrm{b}}$ ) and $\dot{V}_{\mathrm{O}_{2}}$ of the respiratory muscles $\left(\dot{V}_{\mathrm{O}_{2} \mathrm{RM}}\right)$. At peak exercise, $\dot{V}_{\mathrm{O}_{2} \mathrm{RM}}$ accounts for $\sim 10-15 \%$ of whole-body $\dot{V}_{\mathrm{O}_{2}}$ in healthy adult males [55], with the range reflecting variations in maximal $\dot{V}_{\mathrm{E}}$ and aerobic fitness [56]. Although previous work focused on males, a single female subject was noted as having the largest relative oxygen cost of breathing $\left(\dot{V}_{\mathrm{O}_{2} \mathrm{RM}} / \dot{V}_{\mathrm{O}_{2} \max }\right)$ despite not having the highest $\dot{V}_{\mathrm{E}}$ [56]. When directly comparing $\dot{V}_{\mathrm{O}_{2} \mathrm{RM}}$ between the sexes, findings are equivocal [57-59]. Some estimates of $\dot{V}_{\mathrm{O}_{2} \mathrm{RM}}$ are physiologically excessive $\left(>2 \mathrm{~L} \cdot \mathrm{min}^{-1}\right)$ [57], and others only utilised a narrow range of $\dot{V}_{\mathrm{E}}[58,59]$ where no sex differences in $\mathrm{W}_{\mathrm{b}}$ are observed. However, when the $\dot{V}_{\mathrm{O}_{2} \mathrm{RM}}$ is compared between the sexes over a wide range of $\dot{V}_{\mathrm{E}}$ (i.e., $45-100 \%$ maximal $\dot{V}_{\mathrm{E}}$ ), the $\dot{V}_{\mathrm{O}_{2} \mathrm{RM}}$ was greater in females at and above a $\dot{V}_{\mathrm{E}}$ where sex differences in $\mathrm{W}_{\mathrm{b}}$ are evident (i.e., $\sim 55 \mathrm{~L} \cdot \mathrm{min}^{-1}$ ) [26, 60]. Furthermore, the $\dot{V}_{\mathrm{O}_{2} \mathrm{RM}} / \dot{V}_{\mathrm{O}_{2} \max }$ was greater in females than males at $>90 \% \dot{V}_{\mathrm{O}_{2} \max }$ [26]. The higher $\dot{V}_{\mathrm{O}_{2} \mathrm{RM}} / \dot{V}_{\mathrm{O}_{2} \max }$ in females suggests that their respiratory muscles command a greater fraction of whole-body $\dot{V}_{\mathrm{O}_{2}}$, and potentially cardiac output, during high-intensity exercise [61]. In addition to the greater $\mathrm{W}_{\mathrm{b}}$, respiratory muscle efficiency (i.e., $\dot{V}_{\mathrm{O}_{2} \mathrm{RM}} / \mathrm{W}_{\mathrm{b}}$ ) was $\sim 2 \%$ lower in females compared to males [26]. The explanation for the lower respiratory muscle efficiency in females is unknown, but could be due to the work required to stabilise the abdomen and distort the chest wall, which can account for upwards of $25 \%$ of total $\mathrm{W}_{\mathrm{b}}[62,63]$.
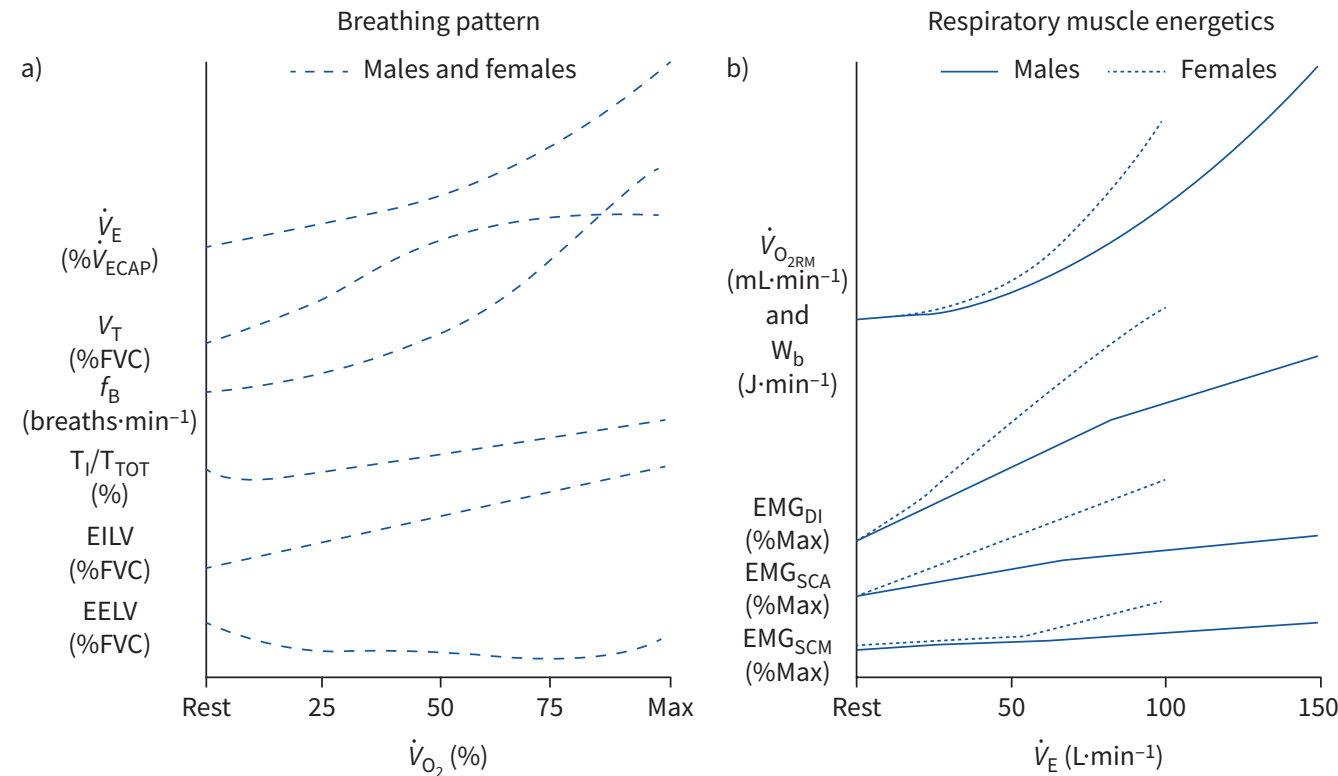

FIGURE 1 Sex differences and similarities in breathing pattern and respiratory muscle energetic responses to incremental exercise. The $x$-axes represent progressive increases in relative oxygen uptake (panel a) and absolute minute ventilation (panel b) from rest to maximal exercise intensity. The $y$-axes are unitless and are intended to illustrate the pattern of change; however, units for each variable are provide in parentheses. In panel $b$, the curves for each sex are extrapolated to the average maximal exercise minute ventilation in healthy, young adults of average cardiorespiratory fitness. EELV: end-expiratory lung volume; EILV: end-inspiratory lung volume; $\mathrm{EMG}_{\mathrm{DI}}$ : electromyographical activity of the diaphragm; $\mathrm{EMG}_{\mathrm{SCA}}$ : electromyographical activity of the scalene; $\mathrm{EMG}_{\mathrm{SCM}}$ : electromyographical activity of the sternocleidomastoid; $f_{\mathrm{B}}$ : breathing frequency; $\mathrm{T}_{1} / \mathrm{T}_{\text {TOT }}$ : inspiratory duty cycle; $\dot{V}_{\mathrm{E}}$ : minute ventilation; $\dot{V}_{\mathrm{O}_{2} \mathrm{RM}}$ : oxygen uptake of the respiratory muscles; $V_{\mathrm{T}}$ : tidal volume; $W_{b}$ : work of breathing. 


\section{Respiratory muscle activation}

In females, the higher $\mathrm{W}_{\mathrm{b}}$ during exercise is accomplished by distributing the load more evenly across several respiratory muscles [31]. Indeed, females have a higher activation of the diaphragm, scalenes, and sternocleidomastoids than males at a given $\dot{V}_{\mathrm{E}}$ during incremental exercise [31] and throughout constant-load exercise at $85 \%$ of $\dot{V}_{\mathrm{O}_{2} \max }$ [32]; however, this finding is not universal [64]. The functional consequences of sex differences in respiratory muscle activation patterns during exercise are unclear, but increasing the activation of "extra-diaphragmatic" inspiratory muscles may influence the propensity towards, and the magnitude of, exercise-induced respiratory muscle fatigue.

\section{Diaphragm fatigue}

During exercise of sufficient intensity and duration (i.e., $>80 \%$ of $\dot{V}_{\mathrm{O}_{2} \max }$ for $>5 \mathrm{~min}$ ), the diaphragm can fatigue [65]. The degree of fatigue is related to the work done by the diaphragm [66, 67]. However, performing the respiratory muscle work associated with the hyperpnoea of intense exercise, but in the absence of exercise itself, does not elicit diaphragm fatigue [68]. Given that females have a greater $\mathrm{W}_{\mathrm{b}}$ and $\dot{V}_{\mathrm{O}_{2} \mathrm{RM}}$ during exercise than males, it is plausible they are more susceptible to exercise-induced diaphragm fatigue. When this hypothesis was tested using magnetic stimulation of the phrenic nerve after exercise, a similar number of males and females developed diaphragm fatigue [69]. However, in those who developed fatigue, the severity immediately post-exercise was greater in males than in females, but the difference diminished over time [69, 70]. The lack of sex differences in the prevalence of exercise-induced diaphragm fatigue agrees with work in other skeletal muscles during dynamic exercise, which may be due to differences in motor neuron activation, muscle perfusion and/or skeletal muscle metabolism, and fibre type properties [71].

\section{Blood flow distribution}

During intense exercise, $W_{b}$ can impact the distribution of cardiac output [72]. For example, acutely manipulating the $\mathrm{W}_{\mathrm{b}}$ during exercise causes reciprocal changes in blood flow to the respiratory and locomotor muscles [73, 74]. This redistribution in blood flow is sympathetically mediated [75] and occurs in both sexes [74]. Given that the relative cost of exercise hyperpnoea is greater in females than in males, the (re)distribution of cardiac output may also be different. Specifically, lowering the $\mathrm{W}_{\mathrm{b}}$ by a similar relative amount in females may result in a greater amount of blood flow being redirected away from the respiratory muscles; however, this assumes that the magnitude of the respiratory muscle metaboreflex is similar between the sexes, which is not the case with isolated exercise (see the Response to small muscle mass exercise section). The physiological rationale for why females may not demonstrate a greater level of blood flow redistribution during exercise is because the exercise-induced increase in muscle sympathetic nerve activity and blood pressure is attenuated in females relative to males [76]. Thus, akin to the experimental findings concerning diaphragm fatigue, the hypothesis regarding a sex difference in blood flow redistribution due to a higher $\mathrm{W}_{\mathrm{b}}$ in females than in males may not hold true and needs to be tested during dynamic whole-body exercise.

\section{Flow limitation}

During intense exercise, some individuals reach their maximal capacity to generate expiratory flow at a given lung volume, which is termed expiratory flow limitation (EFL) and occurs when tidal expiratory flow meets the maximal expiratory flow-volume (MEFV) curve. Although the exact causes are multifactorial and not completely understood, $\sim 50-60 \%$ of healthy, young individuals experience EFL during exercise $[10,25]$. EFL likely occurs due to a relatively low ventilatory capacity (reflected in the size and shape of the MEFV curve), a relatively high ventilatory demand (reflected by $\dot{V}_{\mathrm{E}}$ ), or both. Indeed, those with a "scooped" MEFV curve (i.e., convex relative to the x-axis) have a greater propensity towards EFL during exercise and the shape does not differ based on sex [77]. Aerobic fitness may also impact EFL since aerobically trained individuals generate a greater $\dot{V}_{\mathrm{E}}$ during maximal exercise than untrained individuals but have similar levels of pulmonary function [78]. Since the shape of the MEFV curve and the ability to increase aerobic fitness are similar in males and females, EFL propensity during exercise is also similar between the sexes in healthy adults of average aerobic fitness [10, 25, 79]. However, due to their lower absolute maximal expiratory flows, highly trained females may be more prone to EFL relative to their male counterparts. Evidence for this comes from studies where EFL occurred more frequently in endurance-trained females than in endurance-trained males [13, 25].

Flow can also be limited during inspiration. While expiratory flow is determined by the mechanical properties of the airways, inspiratory flow depends on the force-generating capacity of the inspiratory muscles. Some endurance-trained athletes develop inspiratory flow limitation during near-maximal exercise $[56,80]$. Due to a lower force generating capacity of the inspiratory muscles, females may be more 
susceptible to inspiratory flow limitation than males; however, no studies have systematically measured inspiratory flow limitation in females, let alone compared the occurrence or severity between the sexes.

\section{Pulmonary vasculature}

During exercise, pulmonary blood volume increases due to vascular distention and recruitment to accommodate the increasing demand for pulmonary diffusion. Owing to their smaller lungs and fewer alveoli, females have lower diffusion capacity, membrane diffusion capacity, and pulmonary capillary volume than males $[12,81]$. Diffusion capacity and pulmonary capillary blood volume also change at rest [82] and during exercise throughout the menstrual cycle [83]. A reduced diffusion capacity in females may affect pulmonary gas exchange during intense exercise or under hypoxic conditions. However, when considering diffusion capacity, one must also consider cardiac output and the ratio of the two [84, 85]. Since females typically have a smaller stature and $\dot{V}_{\mathrm{O}_{2} \max }$ than males, they also have a lower cardiac output. When considering the effectiveness of diffusion and vascular recruitment (i.e., the ratio of diffusion to cardiac output), females have an attenuated decline during exercise, suggesting that the lower diffusion is proportional size [12]. Furthermore, any differences in diffusion capacity are eliminated when scaling for lung volume [12].

\section{Blood gas homeostasis and exercise-induced arterial hypoxaemia}

In the majority of individuals of average cardiorespiratory fitness, arterial oxygen tension $\left(P_{\mathrm{aO}_{2}}\right)$ is maintained close to resting levels even during intense exercise. At sea level, resting $P_{\mathrm{aO}_{2}}$ is $\sim 90$ $100 \mathrm{mmHg}$ and is maintained during exercise, regardless of intensity. Although the above description applies to most young healthy males and females of modest fitness levels, there are notable exceptions.

Exercise-induced arterial hypoxaemia (EIAH) occurs when arterial oxygenation decreases below resting levels during exercise [86]. It is estimated that $\sim 50 \%$ of highly trained (i.e., $\dot{V}_{\mathrm{O}_{2} \max }>65 \mathrm{~mL} \cdot \mathrm{kg}^{-1} \cdot \mathrm{min}^{-1}$ ) males develop EIAH [87]. However, firm conclusions regarding the prevalence of EIAH are not possible due to the overall lack of temperature-corrected arterial blood gas data obtained during exercise. Nevertheless, we, and others, have proposed that the likelihood of developing EIAH may differ based on sex. The mechanisms of EIAH are complex and result from incomplete pulmonary gas exchange, mechanical ventilatory constraint and/or inadequate ventilatory drive. There are two pertinent questions with regards to potential sex differences in EIAH: 1) is EIAH more prevalent and severe in females? And 2) can relatively untrained females develop EIAH?

First, although EIAH is estimated to occur in $~ 50 \%$ of trained males, the occurrence in trained females is closer to $\sim 65 \%$ when entire study cohorts are considered and nearly $100 \%$ in females with $\dot{V}_{\mathrm{O}_{2} \max }$ $>50 \mathrm{~mL} \cdot \mathrm{kg}^{-1} \cdot \mathrm{min}^{-1}[38,39]$. When combining multiple studies investigating EIAH, females have a lower $P_{\mathrm{aO}_{2}}$ at $\dot{V}_{\mathrm{O}_{2} \max }$ and a given absolute $\dot{V}_{\mathrm{O}_{2}}$ [88]. However, the greater prevalence and severity of EIAH in females relative to males is not a universal finding $[16,89]$. The discrepancy is likely the result of scaling and the exercise modality utilised. When subjects were matched for lung size, height and fitness, sex differences in EIAH are absent, which suggests that sex per se does not affect gas exchange [16]. The lack of difference in EIAH between lung size-matched males and females aligns with work examining diffusion capacity [12]. The difficulty in drawing conclusions from these studies is that lung size, height, and $\dot{V}_{\mathrm{O}_{2} \max }$ are themselves impacted by sex and eliminating them obscures potential sex differences. Different exercise modalities could also explain the inconclusive findings as those who note a greater prevalence and severity of EIAH in females have utilised treadmill rather than cycle exercise. In the same group of females, treadmill exercise results in a greater decrease in $P_{\mathrm{aO}}$ than cycle exercise [89]. The exact mechanisms underpinning the effect of exercise modality on EIAH is unknown, but is likely due to differences in active muscle mass [89]. Second, EIAH has not been demonstrated in untrained males [50, 88], but has been confirmed in untrained females during treadmill [38, 39, 40], but not cycle, exercise. Thus, females of modest aerobic fitness can develop EIAH. The purported mechanism responsible for EIAH in untrained females is mechanical ventilatory constraints, such as EFL, which limit the compensatory hyperpnoea that normally offsets any gas exchange impairments [38, 90,91]. Overall, we stress that more data is required to determine whether there are sex differences in EIAH.

\section{Perception of dyspnoea}

Dyspnoea refers to the subjective feeling of breathlessness [92]. In the general population, females experience dyspnoea during activities of daily living more frequently than their male counterparts [93]; however, the exact mechanisms remain unclear. Dynamic, whole-body exercise is an excellent model for studying the mechanisms of dyspnoea since the exercise-induced increase in metabolic rate elevates the demands on the pulmonary system, which increases the perception of dyspnoea correspondingly [94]. It follows that controlled laboratory experiments involving dynamic, whole-body exercise could be used to 
uncover the physiological and/or psychological underpinnings of sex differences in the perception of dyspnoea. Indeed, during exercise, the perception of dyspnoea is higher in females than males for a given absolute work rate or $\dot{V}_{\mathrm{E}}[14,95]$, which has been ascribed to sex-difference neural respiratory motor drive [14]. However, sex differences in the perception of dyspnoea are not evident when comparisons are made a relative $\dot{V}_{\mathrm{O}_{2}}$ or $\dot{V}_{\mathrm{E}}[10,25,69,70,96]$. Nevertheless, the qualitative descriptors of exertional dyspnoea differ based on sex, with females reporting descriptors "inspiratory difficulty/unsatisfied inspiration" and "shallow breathing" at peak exercise. The exact mechanisms of sex differences in exertional dyspnoea are unclear, but recent experimental evidence suggests that the higher perception of dyspnoea during exercise in females is unrelated to sex differences in the mechanical ventilatory response to exercise [11].

\section{Exercise performance}

Although we have noted several instances where the pulmonary response to exercise differs between the sexes, it does not appear to have a major impact on exercise performance. For example, lowering the $\mathrm{W}_{\mathrm{b}}$ during a $5 \mathrm{~km}$ cycle time trial had a similar positive effect on performance ( $\sim 1-2 \%$ reduction in time) between the sexes [96]. Similarly, when diaphragm fatigue develops, or if it is induced experimentally, the negative effects on subsequent exercise performance are similar in both sexes [70]. It is well known that reversing any hypoxaemia will improve exercise performance and the magnitude of the improvement is related to the improvement in oxyhaemoglobin saturation, which does not differ based on sex [97]. Overall, differences in endurance-exercise performance between the sexes are primarily attributed to differences in $\dot{V}_{\mathrm{O}_{2} \text { max }}$, which largely arise due to sex differences in haemoglobin concentration, body composition, and societal factors [51].

\section{Response to small muscle mass exercise}

In this section, we describe how sex potentially impacts the physiological response to small muscle mass exercise, typically involving one muscle group (e.g., single leg extension) and/or relatively small groups of muscles (e.g., respiratory muscle loading) (table 1). These experiments allow for detailed measurements of physiological function that would otherwise be too difficult or impossible during whole-body exercise. However, findings from studies involving small muscle mass exercise do not necessarily translate directly to dynamic exercise. Nevertheless, they enable the precise control of confounding variables and can provide insight regarding specific physiological mechanisms.

\section{Diaphragm fatigue and the respiratory muscle metaboreflex}

With a sufficiently high load (typically $>50 \%$ of maximal inspiratory pressure and $>50 \%$ inspiratory duty cycle), the respiratory muscles can fatigue $[98,99]$. As is the case with dynamic, whole-body exercise, the magnitude diaphragm fatigue appears to be similar or greater in males than females during isolated exercise [33] performed at a relative work, and this difference persists even when matched for absolute work [34]. Unfortunately, these studies all rely on magnetic stimulation of the phrenic nerve, a technique that has important limitations (see below).

It is well established that the inspiratory muscle metaboreflex is blunted in healthy young females compared to males. When performing fatiguing inspiratory resistive or threshold breathing, the rise in mean arterial pressure is greater in males compared to females [33, 35, 100]. A blunted inspiratory metaboreflex in females has also been observed during voluntary hyperpnoea, which is more representative of the spontaneous breathing patterns observed during exercise [36, 37]. The blunted metaboreflex in females is likely due to oestrogen upregulation of $\beta_{2}$-adrenergic receptors which promotes vasodilation [101].

When interpreting the evidence related to diaphragm fatigue (during whole-body or isolated exercise) and the respiratory muscle metaboreflex, it is important to consider the methodological shortcomings in nearly all studies. When assessing diaphragm fatigue using magnetic stimulation of the phrenic nerve, stimulus supramaximality must be ensured for consistent neural recruitment. Unfortunately, many studies do not provide this information and those that present a statistical plateau in transdiaphragmatic twitch pressure unlikely represent a true physiological plateau. Evidence for non-supramaximality can be seen when utilising two magnetic stimulators, which increases magnetic field strength, and still no plateau in transdiaphragmatic twitch pressures is demonstrated despite the potentiated twitches being $\sim 15 \mathrm{~cm}_{2} \mathrm{O}$ higher than what is reported using a single stimulator [102]. The lack of supramaximality can result in fatigue being over-estimated with magnetic stimulation and is likely the reason electrical stimulation demonstrates less fatigue after identical stressors [103]. Furthermore, several studies investigating the respiratory muscle metaboreflex have not quantified the work performed by the respiratory muscles, either directly using oesophageal balloon catheters or indirectly using measures of mouth pressure. Overall, we hesitate to make firm conclusions regarding sex differences in diaphragm fatigue until the aforementioned methodological limitations are addressed. 
Sex differences across the lifespan

Throughout the lifespan, sex differences in the structure and function of the respiratory system are evident [104, 105]; however, their presence and magnitude vary, which will influence their effect on the pulmonary physiology of exercise.

\section{Sex differences in the growth, development and ageing of the lungs and airways}

The growth, development, and ageing of the lungs and airways are similar in males and females. In both sexes, the number of alveoli per unit of lung volume is similar, the relationships between lung and airway growth with somatic growth are closely linked, and the effect of healthy ageing on the pulmonary system is similar. However, although the relationship between lung and airway size is similar in male and female infants and children, there is a divergence during adolescence, whereby, for a given stature, males have larger airways than females as of $\sim 14$ years of age, presumably due to hormonal differences post puberty, and this difference persists throughout adulthood [15, 20]. The majority of work characterising the influence of sex on the pulmonary physiology of exercise has been conducted in healthy adults between the ages of 20 and 40 years. This raises an important question: do sex differences in lung and airway morphology also influence the integrative response to exercise in children, adolescents and older adults?

\section{Children and adolescents}

The extent to which sex differences in pulmonary system morphology affect the responses to exercise during adolescence is unclear [106], and carefully-controlled studies in the paediatric population are relatively few. One study noted a decrease in EFL occurrence during exercise in pre- compared to post-pubescent children (90\% versus 33\%) and that the likelihood of experiencing EFL was similar in males and females [107]. Puberty results in significant growth of the lungs and airways such that ventilatory capacity increases disproportionately relative to ventilatory demand, reducing the propensity towards EFL during exercise [108]. However, the above studies do not provide a mechanistic insight due to methodological limitations. First, neither study corrected for the effect of bronchodilation or thoracic gas compression, which overestimates the occurrence of EFL [109], particularly in children [110]. Second, EFL is one of many indicators of mechanical ventilatory constraint [111, 112], and the absence of sex differences in EFL during exercise does not exclude the possibility that sex influences other respiratory mechanical factors such as $\mathrm{W}_{\mathrm{b}}$ and $\dot{V}_{\mathrm{O}_{2} \mathrm{RM}}[25,26]$. Third, the lack of detailed measures in most paediatric exercise studies precludes the ability to determine whether sex differences in respiratory mechanics, pulmonary gas exchange, respiratory muscle fatigue and neurovascular control during exercise occur in those aged $<18$ years. Additional work examining the influence of sex on the pulmonary physiology of exercise in children is required.

\section{Older adults}

Healthy ageing results in progressive changes to the pulmonary system that decrease pulmonary function, alter the mechanics of breathing, and ultimately influence the ventilatory response to exercise [113]. Evidence suggests that the sex differences in the pulmonary physiology of exercise observed in younger adults are maintained and, in some cases, exacerbated in older adults. Nevertheless, there are notable exceptions where sex differences that were apparent in younger adults are absent in their older counterparts.

In older adults, the ventilatory response to incremental exercise is similar between the sexes. Like younger adults, older females have a higher $\mathrm{W}_{\mathrm{b}}$ for a given $\dot{V}_{\mathrm{E}}$ during exercise than older males [10], due to a higher resistive $W_{b}$ [28]. The effects of sex and age on $W_{b}$ are independent [10], implying that sex differences in $\mathrm{W}_{\mathrm{b}}$ during exercise are maintained throughout adulthood. Respiratory muscle recruitment patterns also differ similarly between the sexes in older adults compared to younger adults, with older females relying on "extra-diaphragmatic" inspiratory muscles to a greater extent than older males [31]. The susceptibility to exercise-induced diaphragm fatigue has not been studied in older males and females. Age-related increases in the propensity towards exercise-induced muscle fatigue have been documented in other skeletal muscles $[114,115]$, but it is unclear whether these findings apply to the respiratory muscles. In contrast to younger adults, older females of even modest fitness levels are more susceptible to EFL during exercise than older males [10]. The greater susceptibility to EFL during exercise in older females relative to older males is likely due to the age-related decline in ventilatory capacity and increase in ventilatory demand during exercise, which occurs equally in both sexes, but disproportionally increases the magnitude of mechanical ventilatory constraint during exercise in females due to their lower absolute lung volumes and maximal expiratory flows [10, 91].

During hyperpnoea or inspiratory muscle loading, the mean arterial pressure response is similar in older males and females, suggesting that the sex difference in the respiratory muscle metaboreflex observed in 
younger adults is likely due to hormonal differences that are absent in post-menopausal females relative to age-matched males [37, 100]. Whether or not this observation translates to whole-body exercise, or influences blood flow distribution during exercise, remains unclear; however, it suggests that for a given level of respiratory muscle work, the distribution of blood flow to respiratory and locomotor muscles during exercise is likely similar in older males and females.

Ageing is associated with progressive remodelling of the pulmonary vasculature [116] leading to increased resting pulmonary artery pressure, regardless of sex [117]. However, even after accounting for differences in work rate and body size, older women have a higher pulmonary artery wedge pressure response to lowand moderate-intensity exercise than older males [118]. The efficiency of pulmonary gas exchange is critically dependent on alveolar ventilation, perfusion, and diffusion through the alveolar-capillary membrane [119]. The normative ageing process affects each of these components, thereby decreasing pulmonary gas exchange efficiency. Despite progressive reductions in diffusion capacity and resting $P_{\mathrm{aO}_{2}}$ with age $[120,121]$, older adults of average cardiorespiratory fitness still maintain $P_{\mathrm{aO}_{2}}$ near resting levels during exercise [122]. It is possible that older women may be particularly susceptible to EIAH during exercise; however, this hypothesis awaits testing.

During exercise, the perception of breathlessness is higher in older females than in older males, at absolute [10] and relative $\dot{V}_{\mathrm{O}_{2}}$ [41], and at ventilatory threshold [11]. The mechanisms of sex differences in exertional dyspnoea in older adults are unclear. Though it is tempting to assume that sex differences in airway morphology and their influence on the resistive $\mathrm{W}_{\mathrm{b}}$ during exercise are the root cause of higher exertional dyspnoea in older females than older males, experimental data do not support this postulate. In older adults, when the resistive $\mathrm{W}_{\mathrm{b}}$ is manipulated during moderate-intensity exercise, the perception of dyspnoea is unaltered in both sexes and sex differences in the magnitude of dyspnoea remain apparent [11].

\section{Hormonal differences}

Aside from sex differences in the morphology of the pulmonary system, there are hormonal differences that could potentially impact pulmonary response to exercise. For premenopausal females, the cyclical changes in ovarian hormone concentration within the blood affects resting $\dot{V}_{\mathrm{E}}$ [123]. However, the impact of the menstrual cycle on exercise $\dot{V}_{\mathrm{E}}$ is less clear with some studies showing no impact $[123,124]$ and others the opposite [125]. The variable results are likely due to the inter- and intra-subject variability in the concentration of, and sensitivity to, ovarian hormones [123]. Regardless, neither the menstrual cycle nor oral contraceptive use appears to have a substantial impact on exercise responses [126]. Pulmonary function is also known to change throughout the menstrual cycle with a decrease in forced expired volume in $1 \mathrm{~s}$ and forced vital capacity during the luteal phase [127]. While consistent, the change in pulmonary function is relatively small (i.e., $\sim 5 \%$ ) and unlikely to influence the physiological response to exercise due to the attendant effect of exercise-induced bronchodilation that improves expiratory flow.

\section{Gender differences in the respiratory system's responses to exercise}

When considering the pulmonary system's response to exercise, sex influences physiological factors such as breathing mechanics, pulmonary gas exchange and neurovascular control [128]. In contrast, the influence of gender on the physiological and perceptual responses to exercise has been woefully understudied. Based on the definition of gender [1], it is reasonable to surmise that gender has little, if any, influence on physiological factors related to the pulmonary response to exercise, but likely impacts psychological or perceptual variables. One such example is the perception of dyspnoea. If we assume that dyspnoea is conceptually similar to pain [129], we can begin to understand how gender may influence the magnitude of exertional dyspnoea. It is possible, albeit speculative, that gender roles influence the dyspnoea response to exercise, with the masculine gender norms being associated with tolerance of exertional dyspnoea and feminine gender norms being associated with accepting dyspnoea as a normal response to exercise, as is the case with research involving experimental pain [130]. However, no studies have specifically evaluated the influence of gender on the perception of exertional dyspnoea. Moreover, the dualistic conceptualisation of sex and gender differences in the pulmonary physiology of exercise being either "biological" or "psychological" in nature is likely too simplistic, and future work should consider the influence of both variables on biological and psychosocial factors. Indeed, additional work is required in order to better understand the individual, and perhaps overlapping, influences of sex and gender on the ventilatory and perceptual responses to exercise in healthy individuals.

\section{Summary and conclusion}

The pulmonary system's response to dynamic, whole-body, and isolated exercise in healthy males and females, though largely similar, is known to differ based on sex. These sex differences are most apparent during intense exercise, especially in highly trained athletes. During mild exercise, and in those of average 
aerobic fitness, sex differences in the pulmonary physiology of exercise may still be present but have less physiological consequences. Lifespan changes in the structure and function of the pulmonary system influence the presence and magnitude of sex differences in the pulmonary response to exercise. While sex differences in the pulmonary response to exercise have been extensively studied, the influence of gender has received less attention.

Provenance: Commissioned article, peer reviewed.

Previous articles in this series: No. 1: Cheron C, McBride SA, Antigny F, et al. Sex and gender in pulmonary arterial hypertension. Eur Respir Rev 2021; 30: 200330. No. 2: LoMauro A, Aliverti A. Sex and gender in respiratory physiology. Eur Respir Rev 2021; 30: 210038. No 3: Chowdhury NU, Guntur VP, Newcomb DC, et al. Sex and gender in asthma. Eur Respir Rev 2021; 30: 210067. No 4: Kawano-Dourado L, Glassberg MK, Assayag D, et al. Sex and gender in interstitial lung diseases. Eur Respir Rev 2021; 30: 210105.

Conflict of interest: P.B. Dominelli has nothing to disclose. Y. Molgat-Seon has nothing to disclose.

\section{References}

1 Canadian Institute of Health Research. What is gender? What is sex? https://cihr-irsc.gc.ca/e/48642.html

2 National Institutes of Health. Sex \& Gender. https://orwh.od.nih.gov/sex-gender

3 World Health Organization. Gender, equity and human rights. www.who.int/teams/gender-equity-andhuman-rights

4 Clayton JA, Tannenbaum C. Reporting sex, gender, or both in clinical research? JAMA 2016; 316: $1863-1864$.

5 Beery AK, Zucker I. Sex bias in neuroscience and biomedical research. Neurosci Biobehav Rev 2011; 35: 565-572.

6 Costello JT, Bieuzen F, Bleakley CM. Where are all the female participants in sports and exercise medicine research? Eur J Sport Sci 2014; 14: 847-851.

7 Miller VM. Why are sex and gender important to basic physiology and translational and individualized medicine? Am J Physiol Heart Circ Physiol 2014; 306: H781-H788.

8 Stévant I, Papaioannou MD, Nef S. A brief history of sex determination. Mol Cell Endocrinol 2018; 468: 3-10.

9 Tan WC, Bourbeau J, Hernandez P, et al. Canadian prediction equations of spirometric lung function for Caucasian adults 20 to 90 years of age: results from the Canadian Obstructive Lung Disease (COLD) study and the Lung Health Canadian Environment (LHCE) study. Can Respir J 2011; 18: 321-326.

10 Molgat-Seon Y, Dominelli PB, Ramsook AH, et al. The effects of age and sex on mechanical ventilatory constraint and dyspnea during exercise in healthy humans. J Appl Physiol 2018; 124: 1092-1106.

11 Molgat-Seon Y, Ramsook AH, Peters CM, et al. Manipulation of mechanical ventilatory constraint during moderate intensity exercise does not influence dyspnoea in healthy older men and women. J Physiol 2019; 597: 1383-1399.

12 Bouwsema MM, Tedjasaputra V, Stickland MK. Are there sex differences in the capillary blood volume and diffusing capacity response to exercise? J Appl Physiol 2017; 122: 460-469.

13 Guenette JA, Witt JD, McKenzie DC, et al. Respiratory mechanics during exercise in endurance-trained men and women. J Physiol 2007; 581: 1309-1322.

14 Schaeffer MR, Mendonca CT, Levangie MC, et al. Physiological mechanisms of sex differences in exertional dyspnoea: role of neural respiratory motor drive. Exp Physiol 2014; 99: 427-441.

15 Ripoll JG, Guo W, Andersen KJ, et al. Sex differences in paediatric airway anatomy. Exp Physiol 2020; 105: 721-731.

16 Olfert IM, Balouch J, Kleinsasser A, et al. Does gender affect human pulmonary gas exchange during exercise? J Physiol 2004; 557: 529-541.

17 Dominelli PB, Cross TJ, Ripoll JG, et al. Sex differences in large conducting airway anatomy. J Appl Physiol 2018; 125: 960-965.

18 Sheel AW, Guenette JA, Yuan R, et al. Evidence for dysanapsis using computed tomographic imaging of the airways in older ex-smokers. J Appl Physiol 2009; 107: 1622-1628.

19 Christou S, Chatziathanasiou T, Angeli S, et al. Anatomical variability in the upper tracheobronchial tree: sex-based differences and implications for personalized inhalation therapies. J Appl Physiol 2020; 130: 678-707.

20 Kuo W, Ciet P, Andrinopoulou E-R, et al. Reference values for central airway dimensions on CT images of children and adolescents. Am J Roentgenol 2018; 210: 423-430.

21 Miller MR, Hankinson J, Brusasco V, et al. Standardisation of spirometry. Eur Respir J 2005; 26: 319-338.

22 Garcia-Martinez D, Torres-Tamayo N, Torres-Sanchez I, et al. Morphological and functional implications of sexual dimorphism in the human skeletal thorax. Am J Phys Anthr 2016; 161: 467-477. 
Torres-Tamayo N, Garcia-Martinez D, Lois Zlolniski S, et al. 3D analysis of sexual dimorphism in size, shape and breathing kinematics of human lungs. $J$ Anat 2018; 232: 227-237.

García-Martínez D, Bastir M, Torres-Tamayo N, et al. Three-dimensional analysis of sexual dimorphism in ribcage kinematics of modern humans. Am J Phys Anthropol 2019; 169: 348-355.

Dominelli PB, Molgat-Seon Y, Bingham D, et al. Dysanapsis and the resistive work of breathing during exercise in healthy men and women. J Appl Physiol (1985) 2015; 119: 1105-1113.

Dominelli PB, Render JN, Molgat-Seon Y, et al. Oxygen cost of exercise hyperpnoea is greater in women compared with men. J Physiol 2015; 593: 1965-1979.

Wanke T, Formanek D, Schenz G, et al. Mechanical load on the ventilatory muscles during an incremental cycle ergometer test. Eur Respir J 1991; 4: 385-392.

Molgat-Seon Y, Dominelli PB, Guenette JA, et al. Modelling the effects of age and sex on the resistive and viscoelastic components of the work of breathing during exercise. Exp Physiol 2019; 104: 1737-1745.

Guenette JA, Querido JS, Eves ND, et al. Sex differences in the resistive and elastic work of breathing during exercise in endurance-trained athletes. Exp Physiol 2009; 297: R166-R175.

Peters CM, Leahy MG, Hohert G, et al. Airway luminal area and the resistive work of breathing during exercise in healthy young females and males. J Appl Physiol 2021; 131: 1750-1761.

Molgat-Seon Y, Dominelli PB, Ramsook AH, et al. Effects of age and sex on inspiratory muscle activation patterns during exercise. Med Sci Sport Exerc 2018; 50: 1882-1891.

Mitchell RA, Schaeffer MR, Ramsook AH, et al. Sex differences in respiratory muscle activation patterns during high-intensity exercise in healthy humans. Resp Physiol Neurobiol 2018; 247: 57-60.

Welch JF, Archiza B, Guenette JA, et al. Sex differences in diaphragmatic fatigue: the cardiovascular response to inspiratory resistance. J Physiol 2018; 17: 4017-4032.

Geary CM, Welch JF, McDonald MR, et al. Diaphragm fatigue and inspiratory muscle metaboreflex in men and women matched for absolute diaphragmatic work during pressure-threshold loading. J Physiol 2019; 597: 4797-4808.

Smith JR, Broxterman RM, Hammer SM, et al. Sex differences in the cardiovascular consequences of the inspiratory muscle metaboreflex. Am J Physiol-Regul Integr Comp Physiol 2016; 311: R574-R581.

Shimizu K, Goto K, Ishida K, et al. Blood pressure response during normocapnic hyperpnoea is blunted in young women compared to men. Respir Physiol Neurobiol 2018; 247: 52-56.

Shimizu K, Shiozawa K, Ishida K, et al. Age and sex differences in blood pressure responses during hyperpnoea. Exp Physiol 2021; 106: 736-747.

Dominelli PB, Foster GE, Dominelli GS, et al. Exercise-induced arterial hypoxaemia and the mechanics of breathing in healthy young women. J Physiol 2013; 591: 3017-3034.

Harms CA, McClaran SR, Nickele GA, et al. Exercise-induced arterial hypoxaemia in healthy young women. J Physiol 1998; 507: 619-628.

Dominelli PB, Foster GE, Dominelli GS, et al. Repeated exercise-induced arterial hypoxemia in a healthy untrained woman. Resp Physiol Neurobiol 2012; 183: 201-205.

Ofir D, Laveneziana P, Webb KA, et al. Sex differences in the perceived intensity of breathlessness during exercise with advancing age. J Appl Physiol 2008; 104: 1583-1593.

Mead J. Dysanapsis in normal lungs assessed by the relationship between maximal flow, static recoil, and vital capacity. Am Rev Respir Dis 1980; 121: 339-342.

Martin TR, Castile RG, Fredberg JJ, et al. Airway size is related to sex but not lung size in normal adults. J Appl Physiol 1987; 63: 2042-2047.

Breatnach E, Abbott GC, Fraser RG. Dimensions of the normal human trachea. Am J Roentgenol 1984; 142: 903-906.

Peters CM, Molgat-Seon Y, Dominelli PB, et al. Fiber optic endoscopic optical coherence tomography (OCT) to assess human airways: the relationship between anatomy and physiological function during dynamic exercise. Physiol Rep 2021; 9: e14657-e14657.

Bellemare F, Jeanneret A, Couture J. Sex differences in thoracic dimensions and configuration. Am J Respir Crit Care Med 2003; 168: 305-312.

Whipp BJ, Ward SA, Lamarra N, et al. Parameters of ventilatory and gas exchange dynamics during exercise. J Appl Physiol 1982; 52: 1506-1513.

Otis AB, Fenn WO, Rahn H. Mechanics of breathing in man. J Appl Physiol 1950; 2: 592-607.

Mead J. The control of respiratory frequency. Ann NY Acad Sci 1963; 109: 724-729.

Stickland MK, Lindinger MI, Olfert IM, et al. Pulmonary gas exchange and acid-base balance during exercise. Comp Physiol 2013; 3: 693-739.

1 Joyner MJ. Physiological limits to endurance exercise performance: influence of sex. J Physiol 2017; 595: 2949-2954.

Mead J. Measurement of inertia of the lungs at increased ambient pressure. J Appl Physiol 1956; 9: 208-212.

Mann LM, Granger EA, Chan JS, et al. Minimizing airflow turbulence in women lowers the work of breathing to levels similar to men. J Appl Physiol 2020; 129: 410-418. 
Holmgren A, Herzog P. Work of breathing during exercise in healthy young men and women. Scand J Clin Lab Invest 1973; 31: 165-174.

Aaron EA, Seow KC, Johnson BD, et al. Oxygen cost of exercise hyperpnea: implications for performance. J Appl Physiol 1992; 72: 1818-1825.

Aaron EA, Johnson BD, Seow CK, et al. Oxygen cost of exercise hyperpnea: measurement. J Appl Physiol 1992; 72: 1810-1817.

Eckermann P, Millahn HP. Der Sauerstoffverbrauch der Atmungsmuskulatur bei Frauen [Oxygen consumption of the respiratory musculature in women. With an observation on the efficiency of the respiratory musculature]. Int Z Angew Physiol 1962; 19: 168-172.

Lorenzo S, Babb TG. Oxygen cost of breathing and breathlessness during exercise in nonobese women and men. Med Sci Sport Exer 2012; 44: 1043-1048.

Topin N, Mucci P, Hayot M, et al. Gender influence on the oxygen consumption of the respiratory muscles in young and older healthy individuals. Intl J Sport Med 2003; 24: 559-564.

Dominelli PB, Render JN, Molgat-Seon Y, et al. Precise mimicking of exercise hyperpnea to investigate the oxygen cost of breathing. Resp Physiol Neurobi 2014; 201: 14-23.

Sheel AW, Boushel RC, Dempsey JA. Competition for blood flow distribution between respiratory and locomotor muscles: implications for muscle fatigue. J Appl Physiol 2018; 125: 820-831.

Goldman MD, Grimby G, Mead J. Mechanical work of breathing derived from rib cage and abdominal V-P partitioning. J Appl Physiol 1976; 41: 752-763.

Grimby G, Bunn J, Mead J. Relative contribution of rib cage and abdomen to ventilation during exercise. J Appl Physiol 1968; 24: 159-166.

Ansdell $P$, Škarabot J, Atkinson E, et al. Sex differences in fatigability following exercise normalised to the power-duration relationship. J Physiol 2020; 598: 5717-5737.

Johnson BD, Babcock MA, Suman OE, et al. Exercise-induced diaphragmatic fatigue in healthy humans. J Physiol 1993; 460: 385-405.

Archiza B, Welch JF, Geary CM, et al. Temporal characteristics of exercise-induced diaphragmatic fatigue. J Appl Physiol 2018; 124: 906-914.

Babcock MA, Pegelow DF, Harms CA, et al. Effects of respiratory muscle unloading on exercise-induced diaphragm fatigue. J Appl Physiol 2002; 93: 201-206.

Babcock MA, Pegelow DF, McClaran SR, et al. Contribution of diaphragmatic power output to exercise-induced diaphragm fatigue. J Appl Physiol 1995; 78: 1710-1719.

Guenette JA, Romer LM, Querido JS, et al. Sex differences in exercise-induced diaphragmatic fatigue in endurance-trained athletes. J Appl Physiol 2010; 109: 35-46.

Welch JF, Archiza B, Guenette JA, et al. Effect of diaphragm fatigue on subsequent exercise tolerance in healthy men and women. J Appl Physiol 2018; 125: 1987-1996.

Hunter SK. Sex differences in human fatigability: mechanisms and insight to physiological responses. Acta Physiol 2014; 210: 768-789.

Harms CA, Wetter TJ, McClaran SR, et al. Effects of respiratory muscle work on cardiac output and its distribution during maximal exercise. J Appl Physiol 1998; 85: 609-618.

Harms CA, Babcock MA, McClaran SR, et al. Respiratory muscle work compromises leg blood flow during maximal exercise. J Appl Physiol 1997; 82: 1573-1583.

Dominelli PB, Archiza B, Ramsook AH, et al. Effects of respiratory muscle work on respiratory and locomotor blood flow during exercise. Exp Physiol 2017; 102: 1535-1547.

Dominelli PB, Katayama K, Vermeulen TD, et al. Work of breathing influences muscle sympathetic nerve activity during semi-recumbent cycle exercise. Acta Physiol 2019; 225: e13212.

Katayama K, Smith JR, Goto K, et al. Elevated sympathetic vasomotor outflow in response to increased inspiratory muscle activity during exercise is less in young women compared with men. Exp Physiol 2018; 103: 570-580.

Dominelli PB, Molgat-Seon Y, Foster GE, et al. Quantifying the shape of maximal expiratory flow-volume curves in healthy humans and asthmatic patients. Resp Physiol Neurobi 2016; 220: 46-53.

Saltin B, Blomqvist G, Mitchell JH, et al. A longitudinal study of adaptive changes in oxygen transport and body composition. Circulation 1968; 38: VII-1-VII-78.

Smith JR, Rosenkranz SK, Harms CA. Dysanapsis ratio as a predictor for expiratory flow limitation. Resp Physiol Neurobi 2014; 198: 25-31.

Johnson BD, Saupe KW, Dempsey JA. Mechanical constraints on exercise hyperpnea in endurance athletes. J Appl Physiol 1992; 73: 874-886.

Guzman CA, Summers ED. Pulmonary diffusing capacity during exercise in women. Chest 1973; 64: 678-682.

Sansores RH, Abboud RT, Kennell C, et al. The effect of menstruation on the pulmonary carbon monoxide diffusing capacity. Am J Respir Crit Care Med 1995; 152: 381-384.

Smith JR, Brown KR, Murphy JD, et al. Does menstrual cycle phase affect lung diffusion capacity during exercise? Resp Physiol Neurobiol 2015; 205: 99-104. 
Hsia CCW. Recruitment of lung diffusing capacity: update of concept and application. Chest 2002; 122: 1774-1783.

Hsia CC, Herazo LF, Ramanathan M, et al. Cardiopulmonary adaptations to pneumonectomy in dogs. IV. Membrane diffusing capacity and capillary blood volume. J Appl Physiol 1994; 77: 998-1005.

Dempsey JA, Wagner PD. Exercise-induced arterial hypoxemia. J Appl Physiol 1999; 87: 1997-2006.

Powers S, Dodd S, Lawler J, et al. Incidence of exercise induced hypoxemia in elite endurance athletes at sea level. Eur J Appl Physiol Occup Physiol 1988; 58: 298-302.

Dominelli PB, Sheel AW. Exercise-induced arterial hypoxemia; some answers, more questions. Appl Physiol Nut Meta 2018; 44: 571-579.

Hopkins SR, Barker RC, Brutsaert TD, et al. Pulmonary gas exchange during exercise in women: effects of exercise type and work increment. J Appl Physiol 2000; 89: 721-730.

Walls J, Maskrey M, Wood-Baker $\mathrm{R}$, et al. Exercise-induced oxyhaemoglobin desaturation, ventilatory limitation and lung diffusing capacity in women during and after exercise. Eur J Appl Physiol 2002; 87: 145-152.

McClaran SR, Harms CA, Pegelow DF, et al. Smaller lungs in women affect exercise hyperpnea. J Appl Physiol 1998; 84: 1872-1881.

Parshall MB, Schwartzstein RM, Adams L, et al. An official American Thoracic Society statement: update on the mechanisms, assessment, and management of dyspnea. Am J Respir Crit Care Med 2012; 185: 435-452.

Ekstrom M, Sundh J, Schioler L, et al. Absolute lung size and the sex difference in breathlessness in the general population. PLOS ONE 2018; 13: e0190876.

Laviolette L, Laveneziana P. Dyspnoea: a multidimensional and multidisciplinary approach. Eur Respir J 2014; 43: 1750-1762.

Cory JM, Schaeffer MR, Wilkie SS, et al. Sex differences in the intensity and qualitative dimensions of exertional dyspnea in physically active young adults. J Appl Physiol 2015; 119: 998-1006.

Wilkie SS, Dominelli PB, Sporer BC, et al. Heliox breathing equally influences respiratory mechanics and cycling performance in trained males and females. J Appl Physiol 2015; 118: 255-264.

Dominelli PB, Molgat-Seon Y, Griesdale DEG, et al. Exercise-induced quadriceps muscle fatigue in men and women: effects of arterial oxygen content and respiratory muscle work. J Physiol 2017; 595: 5227-5244.

Roussos CS, Macklem PT. Diaphragmatic fatigue in man. J Appl Physiol Respir Environ Exerc Physiol 1977; 43: 189-197.

Taylor BJ, Romer LM. Effect of expiratory muscle fatigue on exercise tolerance and locomotor muscle fatigue in healthy humans. J Appl Physiol 2008; 104: 1442-1451.

Smith JR, Alexander AM, Hammer SM, et al. Cardiovascular consequences of the inspiratory muscle metaboreflex: effects of age and sex. Am J Physiol Circ Physiol 2017; 312: H1013-H1020.

Joyner MJ, Barnes JN, Hart EC, et al. Neural control of the circulation: how sex and age differences interact in humans. Compr Physiol 2015; 5: 193-215.

Dominelli PB, McNeil CJ, Vermeulen TD, et al. Effect of acetazolamide and methazolamide on diaphragm and dorsiflexor fatigue: a randomized controlled trial. J Appl Physiol 2018; 125: 770-779.

Mador MJ, Rodis A, Magalang UJ, et al. Comparison of cervical magnetic and transcutaneous phrenic nerve stimulation before and after threshold loading. Am J Respir Crit Care Med 1996; 154: 448-453.

Becklake MR, Kauffmann F. Gender differences in airway behaviour over the human life span. Thorax 1999; 54: 1119-1138.

LoMauro A, Aliverti A. Sex differences in respiratory function. Breathe 2018; 14: 131-140.

Harms CA, Cooper D, Tanaka H. Exercise physiology of normal development, sex differences, and aging. Comp Physiol 2011: 1649-1678.

Swain KE, Rosenkranz SK, Beckman B, et al. Expiratory flow limitation during exercise in prepubescent boys and girls: prevalence and implications. J Appl Physiol 2010; 108: 1267-1274.

Emerson S, Kurti SP, Rosenkranz SK, et al. Decreased prevalence of exercise expiratory flow limitation from pre- to postpuberty. Med Sci Sport Exerc 2015; 47: 1503-1511.

Guenette JA, Dominelli PB, Reeve SS, et al. Effect of thoracic gas compression and bronchodilation on the assessment of expiratory flow limitation during exercise in healthy humans. Resp Physiol Neurobi 2010; 170: 279-286.

0 Strozza D, Wilhite DP, Babb TG, et al. Pitfalls in expiratory flow limitation assessment at peak exercise in children: role of thoracic gas compression. Med Sci Sport Exerc 2020; 52; 2310-2319. during exercise. Chest 1999; 116: 488-503.

2 Babb TG. Mechanical ventilatory constraints in aging, lung disease, and obesity: perspectives and brief review. Med Sci Sport Exerc 1999; 31: Suppl. 1, S12-S22.

Janssens J-P. Aging of the respiratory system: impact on pulmonary function tests and adaptation to exertion. Clin Chest Med 2005; 26: 469-484. 
114 Senefeld J, Yoon T, Hunter SK. Age differences in dynamic fatigability and variability of arm and leg muscles: Associations with physical function. Exp Gerontol 2017; 87: 74-83.

115 Yoon T, Doyel R, Widule C, et al. Sex differences with aging in the fatigability of dynamic contractions. Exp Gerontol 2015; 70: 1-10.

116 Mackay EH, Banks J, Sykes B, et al. Structural basis for the changing physical properties of human pulmonary vessels with age. Thorax 1978; 33: 335-344.

117 Lam CSP, Borlaug BA, Kane GC, et al. Age-associated increases in pulmonary artery systolic pressure in the general population. Circulation 2009; 119: 2663-2670.

118 Esfandiari S, Wright SP, Goodman JM, et al. Pulmonary artery wedge pressure relative to exercise work rate in older men and women. Med Sci Sport Exerc 2017; 49: 1297-1304.

119 Zeleznik J. Normative aging of the respiratory system. Clin Geriatr Med 2003; 19: 1-18.

120 Cerveri I, Zoia MC, Fanfulla F, et al. Reference values of arterial oxygen tension in the middle-aged and elderly. Am J Respir Crit Care Med 1995; 152: 934-941.

121 Coffman KE, Carlson AR, Miller AD, et al. The effect of aging and cardiorespiratory fitness on the lung diffusing capacity response to exercise in healthy humans. J Appl Physiol 2017; 122: 1425-1434.

122 Johnson BD, Dempsey JA. Demand vs. capacity in the aging pulmonary system. Exerc Sport Sci Rev 1991; 19: $171-210$.

123 MacNutt MJ, De Souza MJ, Tomczak SE, et al. Resting and exercise ventilatory chemosensitivity across the menstrual cycle. J Appl Physiol 2012; 112: 737-747.

124 Itoh M, Ueoka H, Aoki T, et al. Exercise hyperpnea and hypercapnic ventilatory responses in women. Respir Med 2007; 101: 446-452.

125 Smekal G, Von Duvillard SP, Frigo P, et al. Menstrual cycle: no effect on exercise cardiorespiratory variables or blood lactate concentration. Med Sci Sport Exerc 2007; 39: 1098-1106.

126 Mattu AT, lannetta D, Maclnnis MJ, et al. Menstrual and oral contraceptive cycle phases do not affect submaximal and maximal exercise responses. Scand J Med Sci Sports 2020; 30: 472-484.

127 Farha S, Asosingh K, Laskowski D, et al. Effects of the menstrual cycle on lung function variables in women with asthma. Am J Respir Crit Care Med 2009; 180: 304-310.

128 Dominelli PB, Molgat-Seon Y, Sheel AW. Sex differences in the pulmonary system influence the integrative response to exercise. Exerc Sport Sci Rev 2019; 47: 142-150.

129 Fillingim RB, King CD, Ribeiro-Dasilva MC, et al. Sex, gender, and pain: a review of recent clinical and experimental findings. J Pain 2009; 10: 447-485.

130 Myers CD, Riley JL III, Robinson ME. Psychosocial contributions to sex-correlated differences in pain. Clin J Pain 2003; 19: 225-235. 